\title{
Editorial
}

\section{Minimally invasive direct coronary artery bypass: too young for a trial}

Recently, a variety of novel approaches and ingenious techniques have been developed in an attempt to make cardiac surgical procedures less invasive. ${ }^{1}$ Many of these methods remain largely experimental, yet one procedure seems to have been rapidly accepted by cardiac surgeons. In minimally invasive direct coronary artery bypass (MID$\mathrm{CAB}$ ) the heart is approached via a right or left anterior mini-thoracotomy through which an internal mammary artery is harvested and anastomosed to the targeted coronary artery under direct vision without the use of cardiopulmonary bypass. ${ }^{23}$ Even though the MIDCAB procedure has been used for complex cases, the most common clinical use of MIDCAB has been for single vessel disease, predominantly involving the left anterior descending coronary artery. Indeed, several recent reports have claimed that the clinical outcome of patients managed with this approach is favourable. ${ }^{2-4}$

Not surprisingly, there are calls for randomised controlled trials of MIDCAB against conventional revascularisation or angioplasty in patients with isolated left anterior descending coronary artery disease. ${ }^{56}$ Such trials will certainly be necessary at some stage to establish the role MIDCAB should play in routine practice, nevertheless one must ask the question: is MIDCAB ready for a randomised trial?

Statisticians argue that a randomised trial for a surgical procedure should not, and probably could not, be done during the evolutionary phase of the procedure when skills, experience, technique, philosophies, and even surgical biases of the surgeons are constantly changing. Any of these factors can have a significant effect on outcome, ${ }^{7}$ and the same randomised trial when repeated by different investigators can produce different results.

This is likely to be the case should one compare MIDCAB with conventional revascularisation performed through median sternotomy. While the techniques of conventional surgery are largely uniform, those of MIDCAB vary significantly. Take for example the basic surgical approach used. Some surgeons use thoracoscopic mobilisation of the internal mammary artery while others use a range of techniques and instruments to perform the same task under direct vision, at the expense of not insignificant trauma to the chest wall. ${ }^{8}$ Moreover, some excise a costal cartilage or two, but avoid the need for a rib spreader, while others use spreading that is only achieved by buckling some ribs. Is it correct to group all these techniques together in comparison to median sternotomy when we know for certain that spreading the ribs and not the size of skin incision is the main source of postoperative pain? ${ }^{9}$ Only recently an identical error occurred during the development of videoassisted thoracic surgical techniques, ${ }^{7}$ and the same trap should be avoided with MIDCAB. Indeed, the same issues apply to coronary angioplasty, which is also undergoing rapid evolution. Should we include coronary stenting in our trial, and if so which stent? One thing is certain, not all devices produce the same result.

If given adequate time to mature before being subjected to a trial, it is conceivable that the procedure will become standardised. For instance, thoracoscopic mobilisation of the internal mammary artery will probably become the norm. How crucial is this? With thoracoscopy, full mobilisation of the internal mammary artery can be achieved easily, the length of the graft is not limited, and the need for mammary artery lengthening with other conduits, which has a very uncertain outcome, will die out. In addition, internal mammary artery avulsion ${ }^{10}$ or kinking at its attachment to the chest wall, when incompletely mobilised, are prevented.

Currently, improved dedicated instruments are being developed and tested, and their use will not only reduce chest wall trauma to a truly minimally invasive level but will also facilitate performing the anastomoses, and ultimately improve the success of the procedure. ${ }^{11}$

With MIDCAB still in its infancy, there is little doubt that a learning curve is involved, and current results are likely to represent the early phase of this process. ${ }^{12}{ }^{13}$ Moreover, with more experience skills will develop, improving outcome beyond the learning zone. ${ }^{12}$

Thus, it does not take a big leap of logic to deduce that, with time and further development, the results of MIDCAB will improve. Randomised controlled trials of MIDCAB against other treatments are obviously necessary, but the timing of such trials is crucial. Unless enough time is allowed for the best techniques to be developed and for surgeons to gain experience in their application, it will be difficult for MIDCAB to become a credible contender for the treatment of coronary artery disease. If we pass judgment too early, MIDCAB is bound to lose the vote of confidence.

MOHAMMAD BASHAR IZZAT ANTHONY P C YIM

Division of Cardiothoracic Surgery,

Department of Surgery,

Division of Cardiology,

Department of Medicine,

The Chinese University of Hong Kong,

Hong Kong

emailizzat@mailserv.CUHK.edu.hk

JOHN E SANDERSON

1 Izzat MB, Yim APC. Minimally invasive cardiac surgery, a fleeting fancy or a lasting prospect? [editorial] Int f Cardiol 1997;59:223-5.

2 Acuff TE, Landreneau RJ, Griffith BP, Mack MJ. Minimally invasive coronary artery bypass grafting. Ann Thorac Surg 1996;61:135-7.

3 Calafiore AM, Di Giammarco G, Teodori G, Bosco G, D'Annunzio E, Barsotti A, et al. Left anterior descending coronary artery grafting via left anterior small thoracotomy without cardiopulmonary bypass. Ann Thorac Surg rior small thoracotom

4 Borst C, Jansen EW, Grundeman PF. Less invasive coronary artery bypass grafting: without cardiopulmonary bypass and via reduced surgical access. Heart 1997;77:302-3.

5 Treasure T. Minimal access surgery. Heart 1997;77:304-6.

6 Bryan AJ, Angelini GD. Minimal access coronary artery surgery. Heart 1997;77:307-8.

7 Kirby TJ, Mack MJ, Landerneau RJ, Rice TW. Lobectomy-video-assisted thoracic surgery versus muscle-sparing thoracotomy. $\mathcal{F}$ Thorac Cardiovasc Surg 1995;109:997-1002.

8 Jansen EWL, Beck HJM, Grundeman PF, Bredee JJ. Facilitated exposure of the internal mammary artery in minimally invasive direct-vision CABG. Ann Thorac Surg 1997;63:1797-9.

9 Yim APC. Minimizing chest wall trauma in video assisted thoracic surgery. f Thorac Cardiovasc Surg 1995;109:1255-6.

10 McMahon J, Bergsland J, Arani DT, Salerno TA. Avulsion of the left internal mammary artery after minimally invasive coronary bypass. Ann Thorac Surg 1997;63:843-5. 
11 Izzat MB, Yim APC. Cardiac stabilizer for minimally invasive direct coronary artery bypass. Ann Thorac Surg 1997;64:570-1.

12 Izzat MB, Yim APC. Didn't they do well!? [editorial] Ann Thorac Surg 1997;64:1-2.
13 Nataf P, Lima L, Jault F, Benarim S, Dorent R, Vaissier E, et al. Video-assisted coronary bypass surgery with internal mammary artery: ease [abstract]. F Am Coll Cardiol 1997;29(suppl A):465A

\section{Anastomotic pseudoaneurysm leading to acute tamponade following autograft replacement of the aortic valve}

Pseudoaneurysm is a rare complication of cardiac surgery. The most common predisposing factors are left or right ventriculotomy, placement of a conduit or a right ventricular outflow tract patch, and vascular bypass procedures. The material used, suture technique, infection, progressive vascular disease, poor viability of the structure bordering the graft, and elevated pressure at the anastomosis site are all considered to be responsible in the aetiology of the condition. Echocardiography provides excellent diagnostic information and helps to differentiate between abscess or true aneurysm formation. Early diagnosis is essential if life threatening complications such as infection, embolism, compression of the surrounding structures or rupture leading to tamponade are to be avoided.
The illustrations show a routine echocardiogram recorded eight days after autograft replacement of the aortic valve in a 12 year old boy who underwent surgery because of congenital aortic regurgitation. In parasternal short axis view (left) a pseudoaneurysm (An) is visible adjacent to the aortic root (Ao). The communication of the false aneurysm with the left ventricular outflow tract is clearly seen with Doppler colour flow examination (right) from the same view (RA, right atrium; RV, right ventricle; $\mathrm{PA}$, pulmonary artery).

A few hours after the diagnosis the child developed acute tamponade and collapsed because of rupture of the false aneurysm into the pericardial space. At emergency surgery the aortic suture line was found to have partially dehisced. This was resutured and the patient made a rapid and uncomplicated recovery.

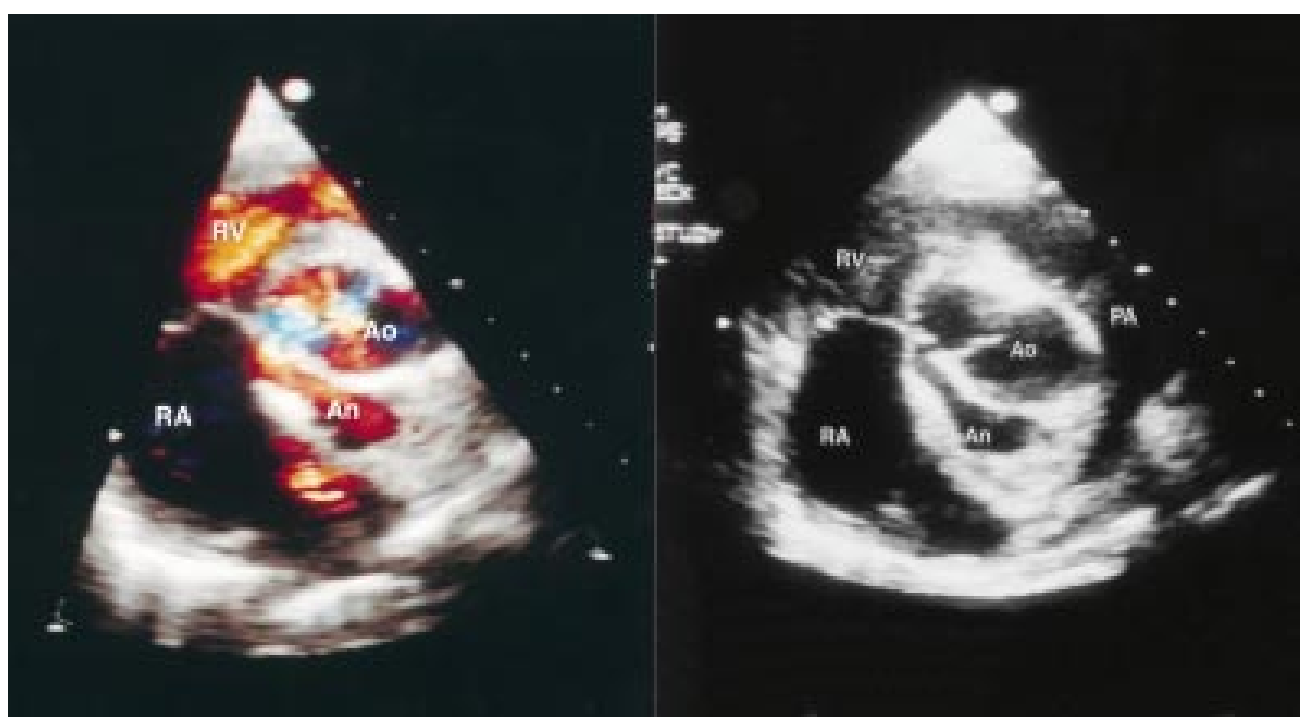

O UZUN 